\title{
A study on the effect of emotional intelligence on retail investors' behavior
}

\author{
Reza Pirayesh*
}

Assistant Professor, Department of Management and Accounting, University of Zanjan, Zanjan, Iran

\begin{tabular}{|c|c|}
\hline CHRON I C LE & ABSTRACT \\
\hline $\begin{array}{l}\text { Article history: } \\
\text { Received Feb } 28,2013 \\
\text { Received in revised format } \\
19 \text { September } 2013 \\
\text { Accepted } 23 \text { October } 2013 \\
\text { Available online } \\
\text { November } 282013 \\
\text { Keywords: } \\
\text { Tehran Stock Exchange } \\
\text { Bias represents }\end{array}$ & $\begin{array}{l}\text { Investment decisions are normally accomplished based on fundamental or technical methods. } \\
\text { However, there are many cases where investors make their investment decisions based on their } \\
\text { emotions. This study investigates the effects of various factors including biases representation, } \\
\text { mental accounting and risk aversion when an investment decision is executed. In other words, } \\
\text { the study examines the effects of emotional intelligence components on retail investors' } \\
\text { investment strategies on Tehran Stock Exchange (TSE). The proposed study selects a sample of } \\
270 \text { investors who had some experiences on TSE randomly and using a questionnaire based } \\
\text { survey detected that there was a positive and meaningful relationship between emotional } \\
\text { intelligence and investment decisions. }\end{array}$ \\
\hline
\end{tabular}

Emotional intelligence

Risk aversion

(C) 2014 Growing Science Ltd. All rights reserved.

\section{Introduction}

Investment decision is one of the most important issues in today's stock market. People make investment decisions based on different fundamental and technical tools. However, there are event when people lose their patients and act emotionally (Ciarrochi et al., 2000, 2001). In such cases, one fatal mistake could create substantial losses for investors. Emotional intelligence (Salovey \& Mayer, 1989; Mayer \& Salovey, 1993; Caruso et al., 2002) is one of the personal characteristics, which plays important role on investment decisions. According to Goleman (2006), emotional intelligence sometimes helps investors make better decision making strategies. According to Mayer et al. (1999) emotional intelligence meets traditional standards for an intelligence.

Sheehan (1999) outlined some of the indicators implying bullying in the workplace as a problem within contemporary firms. In addition, using evidence from some Australian Court cases, the author mentioned some of the expenses firms may be faced with if they fail to address the issues. Having identified the problem, the author recommended some solutions including legislative change and development of more co-operative workplaces. Such workplaces would deal with the issue in a

* Corresponding author. Tel: +98 2415152290

E-mail addresses: r_pirayesh@znu.ac.ir (R. Pirayesh)

(C) 2013 Growing Science Ltd. All rights reserved. doi: $10.5267 / j . m s 1.2013 .11 .037$ 
problem solving, rather than punitive, framework. The author suggested development of people's emotional intelligence skills as a method to help address the problem within such a framework.

Zhang et al. (2011) described early work trying to forecast stock market indicators such as Dow Jones, NASDAQ and S\&P 500 by investigating Twitter posts. They collected the twitter feeds for six months, received a randomized subsample of about 100 of the full volume of all tweets, measured collective hope and fear on each day, and analyzed the correlation between these indices and the stock market signals. They realized that emotional tweet percentage substantially negatively correlated with Dow Jones, NASDAQ and S\&P 500, but displayed substantial positive correlation with VIX. It therefore appeared that just checking on twitter for emotional outbursts of any kind could give a predictor of how the stock market would be doing the next day.

Bekiros (2010) introduced a hybrid neuro-fuzzy system for decision-making and trading under various uncertainty. The author also studied the efficiency of a technical trading strategy based on the neuro-fuzzy to predict the direction of the market for 10 of the most prominent stock indices of U.S.A, Europe and Southeast Asia. The author reported that via an extensive empirical analysis that the neuro-fuzzy model permitted technical analysts to earn substantially higher returns by providing valid information for a potential turning point on the next trading day. The total profit of the proposed neurofuzzy model, including transaction costs, seemed to perform than a recurrent neural network and a Buy \& Hold strategy for all indices, specifically for the highly speculative, emerging Southeast Asian markets. Optimal forecast was based on the dynamic update and adaptive calibration of the heuristic fuzzy learning rules, which indicated the psychological and behavioral patterns of the traders.

Bollen et al. (2011) studied whether measurements of collective mood states derived from large-scale Twitter feeds were correlated to the value of the Dow Jones Industrial Average (DJIA) over time. They investigated the text content of daily Twitter feeds by two mood tracking tools, namely OpinionFinder, which measures positive versus negative mood and Google-Profile of Mood States (GPOMS), which measures mood in terms of 6 dimensions including Calm, Alert, Sure, Vital, Kind, and Happy. They cross-validate the resulting mood time series by comparing their capability to determine the public's response to the presidential election and Thanksgiving day in 2008. They also used a Granger causality analysis and a Self-Organizing Fuzzy Neural Network to study the hypothesis that public mood states, as measured by the OpinionFinder and GPOMS mood time series, were predictive of changes in DJIA closing values. The results stated that the accuracy of DJIA predictions could be substantially improved by the inclusion of specific public mood dimensions but not others. They also reported an accuracy of $86.7 \%$ in predicting the daily up and down changes in the closing values of the DJIA and a reduction of the Mean Average Percentage Error (MAPE) by more than $6 \%$.

\section{The proposed model}

This study investigates the effects of various factors including biases representation, mental accounting and risk aversion when an investment decision is executed (Davies et al. 1998). In other words, the study examines the effects of emotional intelligence components on retail investors' investment strategies on Tehran Stock Exchange (TSE). The proposed study selects the sample size as follows,

$$
N=Z_{\alpha / 2}^{2} \frac{p \times q}{e^{2}},
$$

where $N$ is the sample size, $p=1-q$ represents the probability, $z_{\alpha / 2}$ is CDF of normal distribution and finally $\varepsilon$ is the error term. For our study we assume $p=0.5, z_{\alpha / 2}=1.96$ and $e=0.05$, the number of sample size is calculated as $N=270$. Fig. 1 demonstrates the summary of the proposed model. 


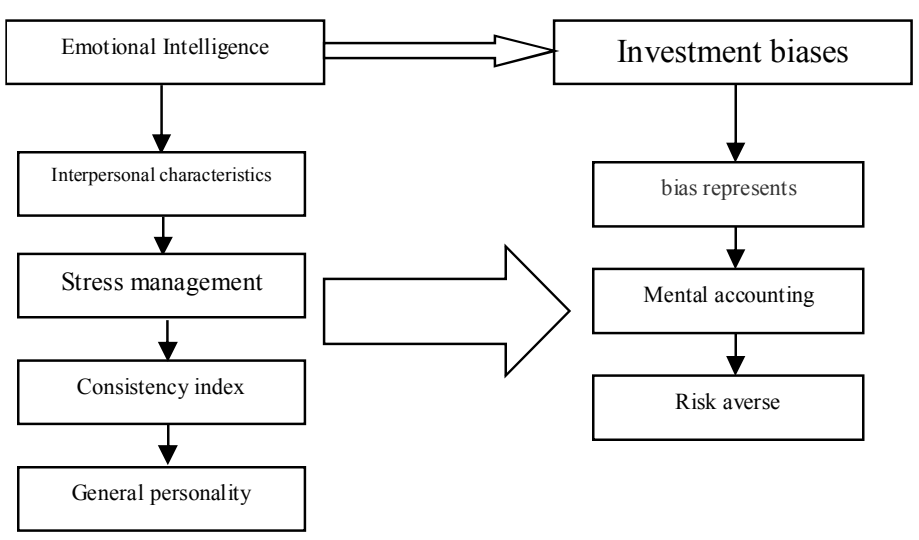

Fig. 1. The proposed model

Based on the components of Fig. 1, the main hypothesis of the survey is as follows,

1. There is a relationship between emotional intelligence and investment decisions.

There are 15 sub-hypotheses associated with the proposed study of this paper. The first three subhypotheses investigate whether there is a meaningful relationship between emotional intelligence on one side and bias represents, mental accounting and risk averse on the other side. The second four hypotheses are as follows,

1. There is a relationship between interpersonal characteristics and bias represents.

2. There is a relationship between stress management and bias represents.

3 . There is a relationship between consistency index and bias represents.

4. There is a relationship between general personality and bias represents.

The third group of hypotheses consists of the following four hypotheses,

1. There is a relationship between interpersonal characteristics and mental accounting.

2. There is a relationship between stress management and mental accounting.

3. There is a relationship between consistency index and mental accounting.

4. There is a relationship between general personality and mental accounting.

The fourth group of hypotheses consists of the following four hypotheses,

1. There is a relationship between interpersonal characteristics and being risk averse.

2. There is a relationship between stress management and being risk averse.

3. There is a relationship between consistency index and being risk averse.

4. There is a relationship between general personality and being risk averse.

The proposed study of this paper used Kolmogorov-Smirnov to find out whether the gathered data were normally distributed or not and the results of our investigation indicated that the data were not normally distributed. Therefore, we use Spearman correlation test to verify different hypotheses. Next, we present details of our survey.

\section{The results}

In this section, we present details of our findings on testing various hypotheses.

\subsection{The main hypothesis: the relationship between emotional intelligence and investment decisions}

The first hypothesis of this survey is associated with the relationship between emotional intelligence and investment decisions. In our survey, the Spearman correlation ratio has been calculated as $\mathrm{r}=0.14$ Sig. $=0.02$, which confirms the first hypothesis of the survey. 


\subsubsection{The first sub-hypothesis: The effect of emotional intelligence}

The first sub-hypothesis of this survey is associated with the effect of emotional intelligence. Table 1 summarizes the results of our investigation.

\section{Table 1}

The summary of testing the first sub-hypothesis: The effect of emotional intelligence

\begin{tabular}{lccc}
\hline Hypothesis & Spearman ratio & Sig. & Result \\
\hline Bias represents & -0.01 & 0.41 & Not confirmed \\
Mental accounting & -0.07 & 0.15 & Not confirmed \\
Risk averse & 0.47 & 0.00 & Confirmed \\
\hline
\end{tabular}

As we can observe from the results of Table 1, only the relationship between emotional intelligence and being risk averse has been confirmed when the level of significance is one percent.

\subsubsection{The second sub-hypothesis: The effect of emotional intelligence}

The second sub-hypothesis of this survey is associated with the effect of bias represent. Table 2 summarizes the results of our investigation.

Table 2

The summary of testing the second sub-hypothesis: The effect of bias represent

\begin{tabular}{lccc}
\hline Hypothesis & Spearman ratio & Sig. & Result \\
\hline Interpersonal characteristics & -0.02 & 0.20 & Not confirmed \\
Stress management & -0.09 & 0.08 & Not confirmed \\
Consistency index & 0.03 & 0.31 & Not confirmed \\
General personality & 0.06 & 0.16 & Not confirmed \\
\hline
\end{tabular}

As we can observe from the results of Table 2, there is not any significant relationship between bias represent and interpersonal characteristics, stress management, consistency index and general personality. Therefore, the second sub-hypothesis of this survey has not been confirmed.

\subsubsection{The third sub-hypothesis: The effect of mental accounting}

The second sub-hypothesis of this survey is associated with the effect of bias represent. Table 3 summarizes the results of our investigation.

Table 3

The summary of testing the third sub-hypothesis: The effect of mental accounting

\begin{tabular}{lccc}
\hline Hypothesis & Spearman ratio & Sig. & Result \\
\hline Interpersonal characteristics & -0.01 & 0.46 & Not confirmed \\
Stress management & -0.04 & 0.25 & Not confirmed \\
Consistency index & 0.01 & 0.47 & Not confirmed \\
General personality & -0.24 & 0.00 & Not confirmed \\
\hline
\end{tabular}

As we can observe from the results of Table 3, there is not any significant relationship between mental accounting and interpersonal characteristics, stress management and consistency and a negative and meaningful relationship with general personality. Therefore, the third sub-hypothesis of this survey has not been confirmed. 


\subsubsection{The fourth sub-hypothesis: The effect of being risk averse}

The fourth sub-hypothesis of this survey is associated with the effect of bias represent. Table 4 summarizes the results of our investigation.

\section{Table 4}

The summary of testing the fourth sub-hypothesis: The effect of being risk averse

\begin{tabular}{lccc}
\hline Hypothesis & Spearman ratio & Sig. & Result \\
\hline Interpersonal characteristics & -0.02 & 0.39 & Not confirmed \\
Stress management & 0.17 & 0.00 & Confirmed \\
Consistency index & 0.069 & 0.00 & Confirmed \\
General personality & 0.16 & 0.00 & Confirmed \\
\hline
\end{tabular}

As we can observe from the results of Table 2, there is not any significant relationship between being risk averse and interpersonal characteristics. However, there is a positive and meaningful relationship between being risk averse on one side and stress management, consistency index and general personality on the other side. Therefore, the fourth sub-hypothesis of this survey has been confirmed.

\section{Conclusion}

In this paper, we have presented an empirical investigation to find the relationship between emotional intelligence and investment decision among retail investors who do trade on Tehran Stock Exchange. The proposed study of this paper has confirmed that there was a positive and meaningful relationship between these two components. The study has also confirmed that when an investors becomes risk averse, he/she will more likely to use his/her emotional intelligence. The study has not confirmed any significant relationship between bias represent and interpersonal characteristics, stress management, consistency index and general personality.

\section{Acknowledgement}

The authors would like to thank the anonymous referees for constructive comments on earlier version of this work.

\section{References}

Bekiros, S.D. (2010). Fuzzy adaptive decision-making for boundedly rational traders in speculative stock markets. European Journal of Operational Research, 202(1), 285-293.

Bollen, J., Mao, H., \& Zeng, X. (2011). Twitter mood predicts the stock market. Journal of Computational Science, 2(1), 1-8.

Caruso, D. R., Mayer, J. D., \& Salovey, P. (2002). Emotional intelligence and emotional leadership. In Kravis-de Roulet Leadership Conference, 9th, Apr, 1999, Claremont McKenna Coll, Claremont, CA, US. Lawrence Erlbaum Associates Publishers.

Ciarrochi, J., Forgas, J. P., \& Mayer, J. D. (Eds.). (2001). Emotional intelligence in everyday life: A scientific inquiry. Philadelphia: Psychology Press.

Ciarrochi, J. V., Chan, A. Y., \& Caputi, P. (2000). A critical evaluation of the emotional intelligence construct. Personality and Individual differences, 28(3), 539-561.

Goleman, D. (2006). Emotional intelligence: Why it can matter more than IQ. Random House Digital, Inc.

Davies, M., Stankov, L., \& Roberts, R. D. (1998). Emotional intelligence: In search of an elusive construct. Journal of personality and social psychology,75(4), 989. 
Mayer, J. D., \& Salovey, P. (1993). The intelligence of emotional intelligence. Intelligence, 17(4), 433-442.

Mayer, J. D., Caruso, D. R., \& Salovey, P. (1999). Emotional intelligence meets traditional standards for an intelligence. Intelligence, 27(4), 267-298.

Salovey, P., \& Mayer, J. D. (1989). Emotional intelligence. Imagination, cognition and personality, $9(3), 185-211$.

Sheehan, M. (1999). Workplace bullying: responding with some emotional intelligence. International journal of manpower, 20(1/2), 57-69.

Zhang, X., Fuehres, H., \& Gloor, P.A. (2011). Predicting stock market indicators through twitter "I hope it is not as bad as I fear". Procedia - Social and Behavioral Sciences, 26, 55-62 